\title{
Beneficial Effects of Oat (Avena sativa L.) Bran Extract in Loperamide-induced Constipated SD Rats
}

\author{
Sung-Gyu Lee ${ }^{1}$, Hyun-Joo Jang ${ }^{2}$ and Hyun Kang ${ }^{1, \dagger}$ \\ ${ }^{I}$ Department of Medical Laboratory Science, College of Health Science, Dankook University, \\ Cheonan-si, Chungnam 31116, Korea, \\ ${ }^{2}$ Taewoong Food Co., Ltd, 21 Chungbuk 27670, Korea
}

The efficacy of extracts of oat (Avena sativa L.) bran in loperamide-induced constipation in SD rats was evaluated. The rats were divided into six groups of five rats each. The animals in Group 1 (control) and Group 2 (constipated control) were administered with distilled water orally. Groups 3, 4 and 5 comprised of constipated rats administered 100, 200 and $300 \mathrm{mg} / \mathrm{kg}$ body weight per day of extract of oat (Avena sativa L.) bran respectively while Group 6 were constipated rats administered bisacodyl $(0.25 \mathrm{mg} / \mathrm{kg}$ body weight). Constipation was induced by oral administration of loperamide. The feeding characteristics, body weight, fecal properties were monitored. The results show that oats (Avena sativa L.) bran possesses laxative effects in loperamide-induced constipated rats.

Key Words: Oat barn, Constipation, Loperamide, Avena sativa L

\section{INTRODUCTION}

Constipation is a functional gastro-intestinal disorder of the general population (Tally et al., 1999) characterized by infrequent or difficult evacuation of feces (Higgins et al., 2004). The use of synthetic drugs such as senna, correctol, exlax, senokot, bisacodyl and gaviscon is very common as a means of treating constipation. Some medicinal plant extracts are known to exhibit antispasmodic effects by stimulating water absorption in the intestine (Palombo, 2006). Oats (Avena sativa L.) have been identified as a whole grain (AACC., 2009), which is defined as a cereal grain that is intact, ground, cracked, or flaked kernel with the endosperm, germ, and bran present in the same relative proportions as the intact grain (De Moura et al., 2004; Okarter, et al., 2010). Oats bran $(\mathrm{OB})$ is very rich in insoluble fiber, consisting mainly of arabinoxylans and, to a lesser extent, cellulose and $\beta$-glucans, as well as vitamins, minerals and antioxidants polyphenolic. OB is involved in the regulation of gastrointestinal physiology and health: delayed gastric emptying and intestinal transit speeds and increases fecal bulk. OB may protect against colorectal cancer and have benefits on inflammatory bowel disease and coeliac disease. A long-term dietary intake of oats or oat bran could benefit inflammatory bowel disorders, but this remains to be proven, as there is no scientific report to substantiate this claim. Therefore, the present study was designed to evaluate the laxative activity of the aqueous root extract of oats (Avena sativa L.) bran in loperamide - induced constipated rats and the effect was

* Received: November 16, 2016 / Revised: December 2, 2016 / Accepted: December 6, 2016

†Corresponding author: Hyun Kang. Department of Medical Laboratory Science, College of Health Science, Dankook University, Cheonan-si, Chungnam 31116, Korea.

Tel: +82-41-550-3015, Fax: +82-41-559-7934, e-mail: hkang@dankook.ac.kr

(C) The Korean Society for Biomedical Laboratory Sciences. All rights reserved.

(C) This is an Open Access article distributed under the terms of the Creative Commons Attribution Non-Commercial License (http://creativecommons.org/licenses/by-nc/3.0/) which permits unrestricted non-commercial use, distribution, and reproduction in any medium, provided the original work is properly cited. 
compared with bisacodyl used as a reference control.

\section{MATERIAL AND METHODS}

\section{Oat bran extraction}

Loperamide hydrochloride and bisacodyl were purchased from Sigma Chemical Co., St Louis, MO, USA. Fresh oat bran was obtained from Chengeup, CheonBook Providence, Korea. Air-dried oat bran was extracted with ten-fold volume of $70 \%$ ethanol in water at room temperature for $72 \mathrm{~h}$. The extracts were collected and concentrated under reduced pressure at $55^{\circ} \mathrm{C}$. The ethanol extract was filtered with cartridge paper (Whatman No 2, Maidstone, England), and then concentrated using a vacuum rotary evaporator (N-1000S-WD, Eyela Co., Tokyo, Japan). Finally, the water extract of ODE was lyophilized (FDU-1100, Eyela Co.) and stored at $-20^{\circ} \mathrm{C}$ before use. The ethanol extract obtained (170 g) was resuspended in water:EtOH $(9: 1, \mathrm{v} / \mathrm{v})$ and partitioned successively with n-hexane, ethyl acetate (EA) and n-butanol to obtain final yields of $19.4,52$ and $27.27 \%$, respectively. EA fraction of $\mathrm{OB}$ extract was dissolved in sterile distilled water and filtered on $0.22 \mu \mathrm{m}$ filters before use. The ethylacetate fraction possessed antioxidant properties.

\section{Animal experiments}

Male Sprague-Dawley rats with an average weight of approximately $120 \mathrm{~g}$ were purchased from Orient, Inc. (Seoul, Republic of Korea). The animals were housed in clean metabolic cages placed in a well-ventilated housing facility. Rats were acclimatized for one week during which they were allowed free access to commercial pelleted rat chow (Bendel feeds and Flour Mill Ltd, Edo State, Nigeria) and water. All experimental procedures were performed in compliance with international policies governing the humane and ethical treatment of experimental animals as contained in the United States National Institutes of Health guidelines (NIH., 1985) after ethical approval by Dankook University. Constipation was induced in the animals by the oral administration of 0.5 $\mathrm{mL}$ of loperamide ( $3 \mathrm{mg} / \mathrm{kg}$ body weight daily for 3 days) (Wintola et al., 2008), while the control rats were administered with distilled water only. The passage of reduced, hard and dry fecal pellets indicated constipation in the rats on the 4th day.

The rats were divided into six groups of five rats each. The animals in Group 1 (control) and Group 2 (constipated control) were administered with distilled water orally. Groups 3, 4 and 5 comprised constipated rats administered 100, 200 and $300 \mathrm{mg} / \mathrm{kg}$ body weight per day of root extract of $\mathrm{L}$. cupanoides respectively while Group 6 were constipated rats administered bisacodyl $(0.25 \mathrm{mg} / \mathrm{kg}$ body weight) (Adams et al., 2008). All oral administration was done using metal oropharyngeal cannula. The water and feed intake, number of fecal pellets and body weight gain of all the rats were recorded during the experimental period. The excreted fecal pellets of individual rats were collected daily throughout the duration of the experiment for one week. The total number, weight and water content of the pellets were determined. The water content was calculated as the difference between the wet and dry weights of the pellet (Wintola et al., 2008). Determined acid phosphatase, alkaline phosphatase, aspartate aminotransferase, $\gamma$-glutaryltransferase and lactate dehydrogenase activities, respectively.

\section{RESULTS AND DISCUSSION}

In the present study, a reduction in the number, weight and water content of fecal pellets following the treatment with the loperamide, which is an indication of constipation in the rats were observed. loperamide prevents the possibility diarrhea by acting on intestinal motility and in turn reducing the water and stools entering the colon (Hughes et., 1984; Lawrence et al., 1984). Table 1 shows the effect of loperamide on feed and water intake, fecal properties and body weight of constipated rats before treatment. Loperamide significantly $(P<0.05)$ reduced the number of fecal pellets and increased significantly $(P<0.05)$ the body weight of the constipated rats compared to the normal rats. This was an indication of constipation. The laxative effect of the extract could also be attributed to changes in the intestinal motility, which produced an increase in intestinal transit and colonic movement (Capasso et al., 2008). Generally, the effect of the treatment with the extract compared favorably well to that of bisacodyl. This is an indication that the herb was effective in ameliorating bowel obstruction, thereby enhancing easy 
Table 1. Effect of Loperamide on feed and water intake, fecal properties and weight of constipated rats before treatment

\begin{tabular}{lcc}
\hline \hline \multicolumn{1}{c}{ Parameters } & Normal rats & Constipated rats \\
\hline Feed intake $(\mathrm{g})$ & $14.56 \pm 0.66$ & $12.46 \pm 0.78$ \\
Water intake $(\mathrm{mL})$ & $27.63 \pm 2.75$ & $28.97 \pm 1.96$ \\
Number of fecal pellet & $53.06 \pm 1.21$ & $44.43 \pm 3.15^{*}$ \\
Water content of fecal pellets $(\mathrm{mL})$ & $2.65 \pm 0.10$ & $2.15 \pm 0.08$ \\
Weight of animals $(\mathrm{g})$ & $123.45 \pm 1.32$ & $134.38 \pm 0.88^{*}$ \\
\hline
\end{tabular}

Data are mean \pm SEM values $(\mathrm{n}=4) ;$ *significantly different from normal control at $P<0.05$

Table 2. Effect of extract of oat bran on feed and water intake, body weight gain and fecal properties of constipated rats on one week

\begin{tabular}{lccccc}
\hline \hline \multicolumn{1}{c}{ Groups } & $\begin{array}{c}\text { Feed intake } \\
(\mathrm{g})\end{array}$ & $\begin{array}{c}\text { Water intake } \\
(\mathrm{mL})\end{array}$ & $\begin{array}{c}\text { No of fecal } \\
\text { pellets }\end{array}$ & $\begin{array}{c}\text { Water in fecal } \\
\text { pellets }(\mathrm{mL})\end{array}$ & $\begin{array}{c}\text { Body weight gain } \\
(\mathrm{g})\end{array}$ \\
\hline Normal control & $13.84 \pm 0.87$ & $30.53 \pm 1.26$ & $59.15 \pm 1.36$ & $2.93 \pm 0.41$ & $11.37 \pm 1.51$ \\
Constipated & $15.16 \pm 0.83$ & $28.03 \pm 0.63$ & $58.59 \pm 2.17$ & $2.12 \pm 0.33^{a}$ & $19.44 \pm 2.38^{a}$ \\
$\mathrm{C}+100 \mathrm{mg} / \mathrm{kg}$ & $15.16 \pm 0.45$ & $30.53 \pm 1.01$ & $28.78 \pm 2.47$ & $2.51 \pm 0.53^{a}$ & $12.36 \pm 1.41^{b}$ \\
C $+200 \mathrm{mg} / \mathrm{kg}$ & $14.34 \pm 0.92$ & $30.03 \pm 1.60$ & $60.15 \pm 1.57$ & $2.93 \pm 0.33$ & $10.27 \pm 1.28^{b}$ \\
C $+300 \mathrm{mg} / \mathrm{kg}$ & $14.53 \pm 0.32$ & $28.59 \pm 0.56$ & $61.4 \pm 4.53$ & $2.37 \pm 0.42^{a}$ & $8.14 \pm 1.33^{b}$ \\
C + Bisacodyl & $14.34 \pm 0.85$ & $29.49 \pm 2.03$ & $61.78 \pm 2.33$ & $3.12 \pm 0.22^{a}$ & $15.12 \pm 1.56^{a b}$ \\
\hline
\end{tabular}

Data are mean \pm SEM values $(\mathrm{n}=4) ;{ }^{a}$ significantly different $(P<0.05)$ compared to the normal control, ${ }^{b}$ significantly different $(P<0.05)$ compared to constipated control

Table 3. Effect of oral administration of extract of oat bran on serum enzymes in normal and loperamide-induced constipated rates

\begin{tabular}{llllll}
\hline \hline \multicolumn{1}{c}{ Group } & ACP $(\mathrm{U} / \mathrm{L})$ & ALP(U/L) & AST(U/L) & y-GT (U/L) & LDH (U/L) \\
\hline Normal control & $1.06 \pm 0.04$ & $1.37 \pm 0.04$ & $1.02 \pm 0.02$ & $0.11 \pm 0.01$ & $0.10 \pm 0.03$ \\
Constipated & $1.07 \pm 0.02$ & $1.88 \pm 0.07^{a}$ & $1.52 \pm 0.04^{a}$ & $0.08 \pm 0.02$ & $0.12 \pm 0.05$ \\
$\mathrm{C}+100 \mathrm{mg} / \mathrm{kg}$ & $0.73 \pm 0.02$ & $1.43 \pm 0.05^{b}$ & $1.23 \pm 0.02$ & $0.10 \pm 0.02$ & $0.14 \pm 0.03$ \\
$\mathrm{C}+200 \mathrm{mg} / \mathrm{kg}$ & $1.81 \pm 0.07^{b}$ & $1.25 \pm 0.04^{b}$ & $1.41 \pm 0.07^{a}$ & $0.05 \pm 0.01$ & $0.20 \pm 0.09$ \\
$\mathrm{C}+300 \mathrm{mg} / \mathrm{kg}$ & $1.67 \pm 0.06^{b}$ & $0.63 \pm 0.03^{a b}$ & $2.02 \pm 0.06^{a b}$ & $0.07 \pm 0.01$ & $0.21 \pm 0.11$ \\
$\mathrm{C}+$ Bisacodyl & $0.67 \pm 0.02$ & $1.06 \pm 0.03^{b}$ & $0.82 \pm 0.02$ & $0.12 \pm 0.01$ & $0.17 \pm 0.01$ \\
\hline
\end{tabular}

Data are mean \pm SEM values $(\mathrm{n}=4)$; ${ }^{a}$ significantly different $(P<0.05)$ compared to the normal control, ${ }^{b}$ significantly different $(P<0.05)$ compared to constipated control

movement in the intestine.

The effect of extract of oats (Avena sativa L.) bran on feed and water intake, body weight gain and fecal properties of constipated rats after treatment is shown in Table 2. There was no significant difference $(P>0.05)$ in the feed and water intake and number of fecal pellets in all the animals. However, the body weight and water in fecal pellets of the constipated rats changed significantly $(P<0.05)$ compared to the normal control. This alteration was counteracted by the administration of extract of oat bran to the SD rats. The activities of lactate dehydrogenase and $\gamma$-glutaryltransferase in the extract treated groups were not significantly different $(P>0.05)$ from the normal control and bisacodyl-treated constipated rats.

There are many enzymes such as phosphatases, dehydrogenases and transferases that are found in appreciable quantities in the serum which did not actually originate from the extracellular fluid. It is only during tissue damage that these 
enzymes leak out of the tissues and become elevated in the serum, making them marker enzymes for safety and or toxicity of pharmacological agents (Pendota et al., 2010). Acid phosphatase is a marker enzymes of lysosomal membrane while alkaline phosphatase is found in the plasma membrane and endoplasmic reticulum. Aspartate aminotransferase is localized in the cells of the liver, kidney and the heart (Akanji et al., 2013). The observed increase in the serum aspartate aminotransferase and acid phosphatase at higher dosages may be due to altered membrane permeability (Reichling et al., 1988). The reduction in the serum alkaline phosphatase may be attributed to the inactivation of the enzyme molecules (Kaplan et al., 1996). However, fluctuations in the activities of these enzymes at some dosages only signify subtle changes in the metabolic processes of the animals.

Whole-grain foods such as oats bran may protect against colorectal cancer and have benefits on inflammatory bowel disease and coeliac disease. A long-term dietary intake of oats or oat bran could benefit inflammatory bowel disorders, but this remains to be proven. The present study points to a laxative effect in loperamide-induced constipated rats by oats (Avena sativa L.) bran. OB can significantly increase stool weight and decrease constipation and it is assumed that this will is able to reduce inflammatory bowel disease.

\section{Acknowledgements}

This research was financially supported by the Ministry of Trade, Industry, and Energy (MOTIE), Korea, under the "Regional Specialized Industry Development Program" supervised by the Korea Institute for Advancement of Technology (KIAT).

\section{Conflicts of interest}

The authors declare that there is no conflict of interests regarding the publication this articles.

\section{REFERENCES}

Adesegun SA, Coker HAB, Hamann MT. Antifungal triterpenoid saponins for Lecaniodiscus cupanioides. Res J Phytochem. 2008. 2: 93-99.
Adams WJ, Meagher AP, Lubowski DZ, King DW. Bisacodyl reduces the volume of polyethylene glycolsolution required for bowel preparation. Dis Colon Rectum. 1994. 3: 229-234.

Akanji MA, Yakubu MT, Kazeem MI. Hypolipidemic and toxicological potential of aqueous extract of Rauvolfiavomitoria afzel root in wistar rats. J Med Sci. 2013. 13: 253-260.

American Association of Cereal Chemists International (AACC). Whole grain task force and definition. AACCI Press. 2009.

Capasso F, Mascolo N, Autore G, Duraccio MR. Effect of indomethacin on aloin and 1, 8 dioxianthraquinoneinduced production of prostaglandins in rat isolated colon. Prostaglandins. 1983. 26: 557-562.

De Moura FF, Lewis KD, Falk MC. Applying the FDA definition of whole grains to the evidence for cardiovascular disease health claims. J Nutr. 2009. 139: 2220-2226.

Higgins PDR, Johanson JF. Epidemiology of constipation in North America: a systematic review. Am J Gastroenterol. 2004. 99: 750-759.

Hughes S, Higgs NB, Turnberg LA. Loperamide has antisecretory activity in the human jejunum in vivo. Gut. 1984. 25: 931-935.

Kaplan LA, Pesce AJ. Clinical Chemistry-Theory, analysis and correlation. Mosby London. 1996. 8: 140-152.

Lawrence RS, Carol ASA, Stephen GM, John SF. Mechanism of the antidiarrheal effect of loperamide. Gastroenterology. 1984. 86: $1475-1480$.

National Institute of Health. Guide for the care and use of laboratory animals. The National Academies Press. 1985.

Okarter N, Liu RH. Health benefits of whole grain phytochemicals. Crit Rev Food Sci Nutr. 2010. 50: 193-208.

Palombo EA. Phytochemicals from traditional medicinal plants used in the treatment of diarrhoea: mode of action and effects on intestinal function. Phytother Res. 2006. 20: 717-724.

Pendota SC, Yakubu MT, Grierson DS, Afolayan AJ. Effect of administration of Hippobromus pauciflorus leaves in male Wistar rats. Afr J Trad CAM. 2010. 7: 40-46.

Reichling JJ, Kaplan MM. Clinical use of serum enzymes in liver disease. Digestive Dis Sci. 1988. 33: 1601-1614.

Talley NJ, Stanghellini V, Heading RC, Koch KL, Malagelada JR, Tytgat GNJ. Functional gastroduodenal disorders. Gut. 1999. 45: 1137-1142.

Thompson WG, Longstreth GF, Drossman DA, Heaton KW, Irvine EJ, Muller-Lissner SA. Functional bowel disorders and functional abdominal pain. Gut. 1999. 45: 1143-1147.

Wintola OA, Sunmonu TO, Afolayan AJ. The effect of aloe ferox mill in the treatment of loperamide-induced constipation in Wistar rats. BMC Gastroenterol. 2010. 10: 95. 